\title{
Synopsis of Part I: The Frieze
}

Introduction -5

1 Context - 17

A Great Trek? - 18

The Afrikaner cause - 26

The Monument committee $-\mathbf{4 0}$

Funding - 51

The site -60

The centenary -65

2 Concept -79

Early ideas - 80

Van Wouw and Moerdyk - 90

Topics for the Great Trek — 118

The role of the architect $-\mathbf{1 4 0}$

Coetzer and the frieze -154

3 Process - 177

The sculptors - 177

Harmony Hall — 188

Models and portraits -217

The full-scale frieze $-\mathbf{2 2 8}$

The plaster casts -247

The frieze in Italy $-\mathbf{2 5 8}$

Homecoming $-\mathbf{2 7 0}$

4 Image -291

Composition - 291

The problem of form - $\mathbf{3 0 2}$

From plaster to marble - $\mathbf{3 3 0}$

The visual narrative - $\mathbf{3 5 2}$

Iconography and ideology - 389

$5 \quad$ Heritage - 395

An Afrikaner monument - 396

Destroyed or redefined? -405

Rebranding the Monument $-\mathbf{4 2 1}$

Representations and rejoinders - 431

Epilogue - 462 
X - Synopsis of Part I: The Frieze

Illustrations Part I -465

Bibliography of works consulted -477

Index of people Part I -499

Index of places Part I $\mathbf{- 5 0 5}$ 